\title{
TRIBUNAL DE JUSTIÇA DO RIO GRANDE DO SUL APELAÇÃO CÍVEL N. 70036136133
}

\section{APELAÇÃO CÍVEL. SERVIDOR PÚBLICO ESTADUAL. CARGA HORÁRIA. REDUÇÃO. FILHO COM NECESSIDADES ESPECIAIS. PREVISÃO LEGAL.}

1. A Lei n. 10.098/94 concede a redução da carga horária de trabalho em até $50 \%$ (cinquenta por cento) para os pais, mães ou responsáveis, que possuam filhos com necessidades especiais, conforme previsão constante de seu art. 127. 2. Requisito de labor de 40 horas semanais atendidos, pela servidora estadual, em que pese em dois vínculos de 20 horas cada. APELAÇÃO DESPROVIDA. (Terceira Câmara Cível, Relator: Rogério Gesta Leal, Data do Julgamento: 01.07.10)

\section{COMENTÁRIO}

\section{Políticas PÚblicas de TRATAMENTO digno da PESSOA DEFICIENTE ENQUANTO DIREITO FUNDAMENTAL INDIVIDUAL E SOCIAL: ESTUDO DE CASO}

\author{
PUBLIC POLITICS ABOUT HUMAN TREATMENTOF DISABLED \\ PERSON AS A FUNDAMENTAL RIGHT: A CASE STUDY
}

Rogério Gesta Leal ${ }^{(*)}$

\section{INTRODUÇÃO}

Pretendo neste ensaio tratar de uma questão que me foi colocada a partir do julgamento de caso judicial junto à minha jurisdição na Terceira Câmara 
Cível, do Tribunal de Justiça do Estado do Rio Grande do Sul, e que envolve direito fundamental híbrido - individual e social ao mesmo tempo -, mais especialmente de deficiente contra familiar (servidor público) Ihe assistindo como condição de possibilidade a uma vida digna.

Para o enfrentamento da matéria, quero primeiro demarcar algumas questões teóricas fundacionais sobre o enquadramento normativo do deficiente como sujeito de direito diferido no sistema jurídico brasileiro.

\section{MARCOS NORMATIVOS E HERMENÊUTICOS DA CONDIÇÃO DO DEFICIENTE NO BRASIL ENQUANTO SUJEITO DE DIREITO FUNDAMENTAL}

Ao menos desde o ano de 1975, a Assembleia Geral da ONU, por meio da Declaração dos Direitos das Pessoas Deficientes, tem reconhecido a importância histórica da proteção dos direitos das pessoas deficientes, e isto fundado nos seguintes argumentos:

a) recordando os princípios da Declaração Universal dos Direitos Humanos, dos Acordos Internacionais dos Direitos Humanos, da Declaração dos Direitos da Criança e da Declaração dos Direitos das Pessoas Mentalmente Retardadas, bem como os padrões já estabelecidos para o progresso social nas constituições, convenções, recomendações e resoluções da Organização Internacional do Trabalho, da Organização Educacional, Científica e Cultural das Nações Unidas, do Fundo da Criança das Nações Unidas e outras organizações afins;

b) lembrando também a Resolução n. 1.921 (LVIII), de 6 de maio de 1975, do Conselho Econômico e Social, sobre prevenção da deficiência e reabilitação de pessoas deficientes, enfatizando que a Declaração sobre o Desenvolvimento e Progresso Social proclamou a necessidade de proteger os direitos e assegurar o bem-estar e reabilitação daqueles que estão em desvantagem física ou mental;

c) tendo em vista a necessidade de prevenir deficiências físicas e mentais e de prestar assistência às pessoas deficientes para que elas possam desenvolver suas habilidades nos mais variados campos de atividades $e$ para promover, o quanto possível, sua integração na vida normal;

\footnotetext{
Pós-Graduação Strictu Sensu da Universidade Estácio de Sá. professor visitante da Università Túlio Ascarelli - Roma Trè, Universidad de La Coruña - Espanha e Universidad de Buenos Aires. Professor da Escola Nacional de Formação e Aperfeiçoamento da Magistratura (ENFAM). Membro da Rede de Direitos Fundamentais (REDIR), do Conselho Nacional de Justiça (CNJ), Brasília. Coordenador Científico do Núcleo de Pesquisa Judiciária, da Escola Nacional de Formação e Aperfeiçoamento da Magistratura (ENFAM), Brasília. Membro do Conselho Científico do Observatório da Justiça Brasileira. Porto Alegre/RS-Brasil. E-mail: grleal@tj.rs.gov.br. Recebido em 25.06.10. Aprovado em 27.06.10.
} 
d) consciente de que determinados países, em seus atuais estágios de desenvolvimento, podem desempenhar apenas limitados esforços para este fim ${ }^{(1)}$.

Neste documento, pode-se visualizar o conceito aproximado de pessoas deficientes como qualquer pessoa incapaz de assegurar, por si mesma, total ou parcialmente, as necessidades de uma vida individual ou social normal, em decorrência de deficiência, congênita ou não, em suas capacidades físicas ou mentais.

Ademais, ainda registra a norma que as pessoas deficientes têm o direito inerente de respeito por sua dignidade humana, qualquer que seja a origem, natureza e gravidade de suas deficiências, tendo os mesmos direitos fundamentais que seus concidadãos, o que implica, antes de tudo, o direito de desfrutar de uma vida decente, tão normal e plena quanto possível. Não bastasse isto, foram sensíveis os legisladores para dispor que as pessoas deficientes devem ter direito a medidas que visem capacitá-las a tornarem-se tão autoconfiantes quanto possível.

Ainda a ONU, em 3 de dezembro de 1982, elaborou o Programa de Ação Mundial para as Pessoas com Deficiência, que diz em seu parágrafo 12 , especificando ainda mais o objetivo de construir condições de igualdade de oportunidades aos deficientes:

"A igualdade de oportunidades é o processo mediante o qual o sistema geral da sociedade - o meio físico e cultural, a habitação, o transporte, os serviços sociais e de saúde, as opor-tunidades de educação e de trabalho, a vida cultural e social, inclusive as instalações esportivas e de lazer - torna-se acessível a todos."

Veja-se que Constituição Federal de 1988 em diversos dispositivos se ocupou da proteção destes sujeitos de direito, a saber: a) em seu art. 7으, $\mathrm{XXXI}$, quando proíbe qualquer discriminação no tocante a salário e critério de admissão do trabalhador portador de deficiência; b) em seu art. 23, II, quando atribui às pessoas jurídicas de direito público interno cuidar da proteção e garantia das pessoas portadoras de deficiência; c) em seu art. 24, XIV, quando determina a competência concorrente da União, Estados e Municípios em matéria de proteção e integração social das pessoas portadoras de deficiência; d) em seu art. 37, VII, quando assegura por lei a reserva de percentual dos cargos e empregos públicos para as pessoas portadoras de deficiência; e) em seu art.203, IV, quando assegura assistência social aos necessitados, com habilitação e reabilitação das pessoas portadoras de deficiência e a promoção de sua integração à vida comunitária; f) em seu art. 203, V, quando garante um salário mínimo ao portador de deficiência que não pode prover sua manutenção; g) em seu art. 208, III, quando impõe ao Estado o dever de dar atendimento educacional especializado aos portadores de

(1) MEC. Disponível em: <http://portal.mec.gov.br/seesp/arquivos/pdf/dec_def.pdf>. Acesso em: 20 jun. 2010. 
deficiência; h) em seu art. 224, quando determina que por lei sejam adaptados logradouros, edifícios e transportes públicos às condições de utilização pelos deficientes; i) em seu art. $227, \S 1^{\circ}$, II, quando obriga a criação de programas de prevenção e atendimento especializado aos deficientes, facilitando o acesso aos bens e serviços coletivos, com a eliminação de preconceitos e obstáculos arquitetônicos.

Em termos de legislação ordinária, tem-se a Lei n. 7.853, de 24.10.89, que dispõe sobre o apoio e integração social dos deficientes e institui a tutela jurisdicional de interesses coletivos ou difusos destas pessoas, definindo, ainda, crimes em relação à matéria, tais como a negação, sem justa causa, a alguém, por motivos derivados de sua deficiência, de emprego ou trabalho, assim como impedimento, sem justa causa, do acesso a qualquer cargo público, por idêntico motivo, estipulando pena de reclusão de um a quatro anos.

Na mesma direção, vai a Lei n. 7.405 , de 12 de novembro de 1985, que dispôs sobre o Símbolo Internacional de Acesso para utilização por pessoas portadoras de deficiência, e a Lei n. 8.899, de 19 de junho de 1994, que concede passe livre aos portadores de deficiência no sistema de transporte coletivo interestadual.

Estados e Municípios, da mesma forma têm, no âmbito de suas competências, regulamentado vários destes direitos estabelecidos pela Constituição Federal e pelas Leis Ordinárias referidas. Inclusive no que tange às relações de trabalho, conta-se com a Lei n. 8.213/91, que introduziu reserva de mercado aos deficientes, obrigando as empregadoras reservar certo número de cargos em percentuais aos beneficiários reabilitados ou pessoas portadoras de deficiências.

É sintomático que a referida Lei Federal n. 7.853/89, refira logo em seu art. 1ㅇ, que na aplicação dos seus termos importa considerar os valores básicos da igualdade de tratamento e oportunidade, da justiça social, do respeito à dignidade da pessoa humana, do bem-estar, e outros, indicados na Constituição ou justificados pelos princípios gerais do direito. Além disto, assevera que suas normas visam garantir às pessoas portadoras de deficiências as ações governamentais necessárias ao seu cumprimento, bem como o acatamento das disposições constitucionais e legais que lhes concernem.

Significa dizer, em outras palavras, que o Estado deve gerar políticas públicas de gestão dos interesses daquelas pessoas - demarcados normativa e faticamente - com ações especiais ao seu desiderato ${ }^{(2)}$.

Por tais razões, é que o Decreto Federal n. 3.298/99, que regulamentou a Lei Federal n. 7.853/89, dispôs sobre a Política Nacional para a Integração da Pessoa Portadora de Deficiência, desde logo afirmando que cabe aos

(2) Ver IBDD. Disponível em: <http://www.ibdd.org.br/arquivos/leis/Decreto\%203.298_99.pdf>. Acesso em: 21 jun. 2010. 
órgãos públicos assegurar à pessoa portadora de deficiência o pleno exercício de seus direitos básicos, inclusive dos direitos à educação, à saúde, ao trabalho, ao desporto, ao turismo, ao lazer, à previdência social, à assistência social, ao transporte, à edificação pública, à habitação, à cultura, ao amparo à infância e à maternidade, e de outros que, decorrentes da Constituição e das leis, propiciem seu bem-estar pessoal, social e econômico ${ }^{(3)}$.

Aliado a isto, previu este dispositivo também os princípios informativos das políticas públicas voltadas à pessoa deficiente, a saber, dentre outros: o desenvolvimento de ação conjunta do Estado e da sociedade civil, de modo a assegurar a plena integração da pessoa portadora de deficiência no contexto socioeconômico e cultural; o estabelecimento de mecanismos e instrumentos legais e operacionais que assegurem às pessoas portadoras de deficiência o pleno exercício de seus direitos básicos que, decorrentes da Constituição e das leis, propiciam o seu bem-estar pessoal, social e econômico(4).

Quero sustentar aqui que estes universos de normas postas pelo sistema jurídico devem dialogar entre si, a partir da lógica que se insere naquilo que Wittgenstein $^{(5)}$ denominou de jogo de linguagens, isto é, num conjunto que se constitui, em verdade, de ações coletivas que vão gerando enunciações que, fora de seus contextos, perdem substância e compreensão.

Significa dizer que as normas protetivas dos interesses de pessoas portadoras de deficiências formam, de modo inseparável, discursos normativos e práticas políticas cotidianas, que precisam guardar coerência e pertinência em face dos contextos a que pertencem. Em outras palavras, tal postura implica a adoção e o reconhecimento de uma metodologia de interpretação e aplicação do direito de forma a evidenciar/denunciar seus compromissos fundamentais; significa criar um instrumental de operacionalização da norma jurídica e de sua concretude cotidiana, deixando de lado a concepção de que o conceito de sistema jurídico positivo se apresenta como um simples sistema de ideias despolitizado, articulado em nome da ciência e objetividade do ordenamento e da norma jurídica.

(3) Art.2º, do Decreto Federal n. 3.298/99.

(4) Art.5o, do mesmo diploma. O art. 6oㅡ. por sua vez, trata das Diretrizes das Políticas Públicas voltadas a estas pessoas, dizendo: "Art. 6ำ São diretrizes da Política Nacional para a Integração da Pessoa Portadora de Deficiência: I — estabelecer mecanismos que acelerem e favoreçam a inclusão social da pessoa portadora de deficiência; II - adotar estratégias de articulação com órgãos e entidades públicos e privados, bem assim com organismos internacionais e estrangeiros para a implantação desta Política; III - incluir a pessoa portadora de deficiência, respeitadas as suas peculiaridades, em todas as iniciativas governamentais relacionadas à educação, à saúde, ao trabalho, à edificação pública, à previdência social, à assistência social, ao transporte, à habitação, à cultura, ao esporte e ao lazer; IV - viabilizar a participação da pessoa portadora de deficiência em todas as fases de implementação dessa Política, por intermédio de suas entidades representativas; $V$ ampliar as alternativas de inserção econômica da pessoa portadora de deficiência, proporcionando a ela qualificação profissional e incorporação no mercado de trabalho; e VI - garantir o efetivo atendimento das necessidades da pessoa portadora de deficiência, sem o cunho assistencialista." (5) WITTGENSTEIN, Ludwig. Investigações filosóficas. São Paulo: Abril Cultural, 1984. 
Estou propondo, junto com Lamego ${ }^{(6)}$, que o intérprete da lei não decodifica apenas um sistema de signos, mas interpreta um texto que é ao mesmo tempo contexto. Subjacente a este conjunto de ideias está a rejeição de uma concepção de linguagem com função meramente instrumental - a linguagem como signo ou mera forma simbólica - considerando-a, ao invés, como uma instituição social complexa, partindo do pressuposto de que as expressões têm sentido apenas no contexto dos distintos jogos de linguagem, complexos de discurso e de ação.

Até mesmo hermeneutas tradicionais como Dilthey ${ }^{(7)}$ vão tomar como pressuposto fundamental que o texto/realidade a interpretar é a própria realidade, juntamente com o seu encadeamento no mundo dos homens, pois, antes da coerência de um texto, vem a da história, considerada pelo autor como um grande referencial identificador do indivíduo temporalizado e espacializado. Este homem, assim, não é um estranho para o seu semelhante, pois dá sinais de sua própria existência, perceptíveis e mesmo constituídos por seus pares, criando provas físicas e inteligíveis ao longo do seu processo de desenvolvimento: sistemas culturais, a filosofia, a arte e a religião, e o Direito. É preciso, então, interpretar os signos objetivados nestas estruturas sociais significadas/significantes.

Já mais contemporaneamente, em Gadamer, a atividade de interpretação e atribuição de sentido é sempre realizada por um sujeito histórico que parte de condições espaciais e temporalmente dadas, contando também com estruturas prévias de pré-compreensão, significando que em todo o processo de compreensão há pressupostos ou pré-juízos - no sentido etimológico de juízos prévios - que viabilizam e constituem certa memória cultural presente em teorias, mitos, tradições etc. ${ }^{(8)}$. Entende-se com isto que o sujeito que compreende não parte do zero, mas, ao contrário, conta com toda uma história que the caracteriza e mesmo o define como sujeito: a tradição. Assim:

(6) LAMEGO, José. Hermenêutica e jurisprudência: análise de uma recepção. Lisboa: Fragmentos, 1990. p. 39 e ss.

(7) DILTHEY, Wilhelm. Introduction to the human sciences: an attempt to lay a foundation for the study of society and history. Detroit: Wayne State University Press, 1987. Na contribuição de Dilthey, por fim, se percebe que a compreensão de um determinado texto/realidade se institui a partir da compreensão de um outrem que aí se exprime, sendo este o momento em que se percebe o deslocamento do objeto da hermenêutica do sentido e da referência do texto para o plano de existência conjuntural e histórica que nele se encontra, notadamente a partir da subjetividade que o criou. Ver também o texto de MENGONI, Luigi. Ermeneutica e dogmatica giuridica. Milano: Giuffrè, 1996. p. 59 e ss.

(8) Conforme GADAMER, Hans Georg. Verdade e método. Rio de Janeiro: Vozes, 1997. Entende-se, então, que, para o filósofo alemão as palavras não são algo que pertencem ao homem, mas sim à situação; elas não são meramente signos de que se possa apropriar; também não são algo existente que se possa modelar ou pelo qual se atribui significados, fazendo com o que o signo torne visível outra coisa, mas se afigura como a idealidade dos significados que reside nas palavras. As palavras já são, por conseguinte, sempre significativas. 
Gadamer denuncia el prejuicio de todo antiprejuicio. Los prejuicios o presupuestos son constitutivos de la realidad histórica del ser humano, son condiciones a priori de la comprensión, y la pretensión historicista y cientifista de eliminar todo prejuicio es, a su vez, un prejuicio, pero en el sentido de un falso prejuicio. Este afán por desembarazarse de todo prejuicio (que ya se halla en Descartes, que quería evitar toda precipitación y prevención, y que se desarrolla durante la llustración) pretendía una comprensión libre de presupuestos. Pero tal pretensión no es posible, y revela una concepción psicologista que pretende la posibilidad de una comprensión basada en una coexistencia atemporal entre el intérprete y lo interpretado. Ante este psicologismo, Gadamer defiende una concepción ontológica basada en la temporalidad del ser de ambos polos: autor y intérprete. Por ello postula la necesidad de una distancia temporal en el proceso de la comprensión. Dicha distancia temporal es productora de sentido y es la que permite desembarazarse de los falsos prejuicios para permitir destacar aquellos otros prejuicios que ofrecen el camino de la comprensión. ${ }^{(9)}$

Nesta perspectiva, a compreensão não se aloja fundamentalmente numa atividade subjetiva do intérprete, mas em sua entrada no processo da tradição, em que passado e presente se condicionam constantemente. Assim, a antecipação de sentido que abrange toda a tradição deveria levar à compreensão de que as próprias partes determinam o todo, e que ela deveria procurar não só seguir suas antecipações, mas consciencializar-se delas a fim de controlá-las e conseguir alcançar uma compreensão correta das coisas ${ }^{(10)}$.

No âmbito específico da aplicação do sistema jurídico para solver problemas concretos e cotidianos - pela via jurisdicional -, pelo fato deles se apresentarem com um grau de complexidade ampliado pela fenomenologia do mundo da vida em que acontecem, é ingênua a pretensão de apreendê-los de forma exaustiva e perfeita a partir dos moldes fixados na norma jurídica (tão somente), isto porque a relação entre norma e fato é tensa e conflituosa, não meramente subsuntiva, como tem sido operado pela maior parte da jurisdição brasileira ao longo dos tempos. A dimensão sempre nova dos fatos, atos e negócios que se apresentam ao sistema jurídico (independentemente de suas fórmulas e códigos) não é meramente subjetiva ou idealista - porque parte unicamente da capacidade de compreensão do intérprete que a maneja -, mas é materialmente real, porque são no e com o mundo que os constituem e que é constituído por eles ${ }^{(11)}$.

(9) RIU, Antoni Martinez. Diccionario de filosofia. Madrid: Herder, 1997. p. 298.

(10) GADAMER, Hans-Georg. El giro hermenéutico. Madrid: Catedra, 1997. p.37. Significa dizer que a compreensão começa com algo que se nos dirige e que necessita, em princípio, da suspensão dos nossos preconceitos.

(11) Ver neste sentido o trabalho de STRECK, Lênio Luis. Hermenêutica jurídica em crise. Porto Alegre: Livraria do Advogado, 2003. v. também LEAL, Rogério Gesta. Hermenêutica e direito: considerações sobre a teoria do direito e os operadores jurídicos. Santa Cruz do Sul: Edunisc, 2000. 
Este universo de contingências e necessidades que marcam o fluxo das relações societais, ratifica a importância das advertências de Gadamer, notadamente quanto aos cuidados em se interpretar as normas que regem o agir humano. Em face disto, a objetividade do processo de conhecimento/ compreensão (Sachlichkeit) sugerida pelo autor alemão, funda-se no fato de que aquilo que se revela não constitui uma simples projeção da subjetividade do intérprete da norma, mas diz respeito a algo que atua sobre a sua compreensão quando se apresenta. O que significa dizer que a experiência - neste caso, a da interpretação e aplicação do direito — não se restringe a uma atividade do sujeito, mas se apresenta como uma atuação da própria situação (tradição e mundo da vida) sobre este sujeito, envolvendo-o sem muitas possibilidades de controle absoluto dos seus resultados. ${ }^{(12)} \mathrm{Na}$ dicção do autor alemão:

"A compreensão somente alcança sua verdadeira possibilidade, quando as opiniões prévias, com as quais ela inicia, não são arbitrárias. Por isso, faz sentido que o intérprete não se dirija aos textos diretamente, a partir da opinião prévia que lhe subjaz, mas que examine tais opiniões quanto à sua legitimação, isto é, quanto à sua origem e validez." (13)

E é da legitimidade das normas protetivas dos direitos das pessoas deficientes sob comento que se retira a força vinculante e a autoaplicabilidade de suas disposições, eis que retratam luta histórica por reconhecimento e importância após décadas de esquecimento e mesmo exclusão social. Em face disto, toda e qualquer ação interpretativa/aplicativa dos ordenamentos jurídicos atinentes à espécie não poderão perder de vista os objetivos e finalidades perseguidos no particular, dados pelas diretrizes, princípios e políticas públicas nacionais voltadas a estes sujeitos de direito(14).

Quero dizer, ao fim e ao cabo, que se deve buscar sempre o desenvolvimento de ações conjuntas do Estado e da sociedade civil,

de modo a assegurar a plena integração da pessoa portadora de deficiência no contexto sócio-econômico e cultural; o estabelecimento de mecanismos e instrumentos legais e operacionais que assegurem às pessoas portadoras de deficiência o pleno exercício de seus direitos básicos que, decorrentes da Constituição e das leis, propiciam o seu bem-estar pessoal, social e econômico.

(12) Até porque muitas das forças que delimitam os condicionamentos culturais, morais e éticos dos agentes jurídicos, sequer são conscientes, fazendo parte de um habitus alienante e reificador de visões de mundo pré-constituídas. Neste ponto, ver o trabalho de HABERMAS, Jürgen. Escritos sobre moralidad y eticidad. México: Paidós, 2002. p. 67 e ss.

(13) GADAMER, Hans Georg. Verdade e método, cit., p. 403 (272 do original).

(14) Quero emprestar a estes elementos normativos a compreensão de que representam conjuntos de dispositivos para além das regras jurídicas, pois veiculadoras de políticas, isto é, um tipo de norma cujo objetivo é o bem-estar geral da comunidade, no sentido do seu improvement (melhora) econômico, político e social. Esta ideia normativa remete a Dworkin, quando afirma que ela representa verdadeiro requisito de justiça ou equidade, ou ainda de alguma outra dimensão da moral. Conforme DWORKIN, Ronald. Freedom's law: the moral reading of the American constitution. Cambridge, Massachusetts: Harvard University Press, 1996. p. 47. 
Traçadas estas premissas, passo a enfrentar o caso concreto julgado junto ao Tribunal de Justiça do Estado do Rio Grande do Sul.

\section{O CASO CONCRETO}

O caso que me fora submetido diz com recurso de apelação cível interposta pelo Estado do Rio Grande do Sul nos autos da ação ordinária ajuizada por servidora pública estadual, em face da sentença que julgou procedente o pedido da autora para reconhecer o direito de ter reduzida a sua carga horária normal, em até $50 \%$ em ambos os vínculos, na forma do art.127, da Lei n. 10.098/94. Diante do resultado, o Estado foi condenado ao pagamento das custas processuais e dos honorários advocatícios, estes fixados em $R \$ 800,00$ (oitocentos reais) $^{(15)}$.

Em suas razões, o Estado do Rio Grande do Sul alegou não ser possível a redução de $50 \%$ da carga horária para servidores com vínculo de 20 horas semanais, em uma ou duas matrículas, como é o caso da apelada. Disse que a autorização para afastamento não pode ocorrer de forma irrestrita, haja vista que a Administração Pública está adstrita ao princípio da legalidade, inexistindo respaldo legal a amparar a pretensão da autora. Pugnou pelo provimento do recurso.

A Procuradoria de Justiça opinou pelo desprovimento do recurso.

Em verdade, a servidora estadual, ocupante do cargo de professora, cumpria jornada semanal de 40 horas semanais de trabalho, tendo ingressado com a presente ação objetivando a prorrogação da redução de carga horária obtida administrativamente, para se dedicar à filha, que é portadora de necessidades especiais.

Relatou que sua descendente sofre de epilepsia (CID G40.9), retardo mental leve (CID F70.0), distúrbios da atividade e da atenção (CIDF90.0), e outros transtornos globais do desenvolvimento (CID F84.8), razão pela qual necessita de permanente acompanhamento, sendo este indispensável para que the seja proporcionado um viver condigno. Tais deficiências restaram provadas nos autos e sequer foram contestadas pela Administração Pública.

No caso específico das normativas que regem os servidores públicos gaúchos, o benefício pretendido encontra-se expressamente previsto na LC-RS n. 10.098/94, nos seguintes termos: "Art. 127. O servidor, pai, mãe ou responsável por excepcional, físico ou mental, em tratamento, fica autorizado a se afastar do exercício do cargo, quando necessário, por período de até $50 \%$ (cinquenta por cento) de sua carga horária normal cotidiana, na forma da lei."

(15) Apelação Cível n. 70036136133, Relatoria Des. Rogério Gesta Leal, julgado de forma unânime pela Terceira Câmara Cível do Tribunal de Justiça do Estado do Rio Grande do Sul. 
A lei estadual referida no artigo supracitado, in fine, é a n. 7.868/83, que assim dispõe:

Art. $1^{\circ}$ As servidoras públicas estaduais, mães de excepcionais em tratamento, com carga horária igual ou superior a 44 horas semanais, ficam autorizadas a se afastarem da repartição durante um dos turnos.

$\S 1^{\circ} \mathrm{O}$ afastamento de que trata o "caput" dependerá de requerimento da interessada ao titular ou dirigente máximo do órgão em que estiver lotada e será instruído com certidão de nascimento e atestado médico de que o filho excepcional se encontra em tratamento e necessita assistência direta da mãe.

$\S 2^{\circ} A$ autoridade referida no parágrafo anterior encaminhará $o$ expediente à Secretaria da Saúde e do Meio Ambiente, com vistas ao Departamento de Perícia Médica, que emitirá laudo conclusivo sobre o requerimento.

$\S 3^{\circ}$ A licença de que trata esta Lei será concedida pelo prazo máximo de 6 (seis) meses, podendo ser renovada, sucessivamente, por iguais períodos, observado, sempre o procedimento de que tratam os $\S \S 1^{\circ}$ e $2^{\circ}$.

Art. $2^{\circ}$ Revogadas as disposições em contrário, esta Lei entrará em vigor na data de sua publicação.

O problema aqui, como se viu, diz com a imposição de requisitos restritivos ao acesso da licença pelos termos de Lei Ordinária n. 7.868/83, exigindo contrato de trabalho igual ou superior a 44 horas semanais, em face da Lei Complementar superveniente n. 10.098/94, que diante de sua natureza regulatória dos demais dispositivos federais - inclusive constitucionais e internacionais - , não apresentou tal especificidade restritiva do direito à licença, o que fez muito bem, convergente com os objetivos, finalidades, diretrizes, princípios e políticas públicas nacionais consectárias e já mencionadas.

Mas então, como resolver este aparente conflito de normas?

No campo da Teoria do Direito, Norberto Bobbio sustentava que as regras fundamentais para a solução das antinomias são três ${ }^{(16)}$ : a) o critério cronológico; b) o critério hierárquico; c) o critério da especialidade. 0 critério cronológico, chamado também de lex posteriori, é aquele com base no qual, entre duas normas incompatíveis, prevalece a norma posterior: lex posterior derogat priori. O critério hierárquico, chamado também de lex superior, é aquele pelo qual, entre duas normas incompatíveis, prevalece a hierarquicamente superior: lex superior derogat inferiori. Já o terceiro critério, dito justamente de lex specialis, é aquele pelo qual, de duas normas incompatíveis,

(16) BOBBIO, Norberto. Teoria dell'ordinamento giuridico. Milano: Giappichelli, 1985. p. 97. 
uma geral e uma especial (ou excepcional), prevalece a segunda: lex specialis derogat generali. Aqui também a razão do critério não é obscura: lei especial é aquela que anula uma lei mais geral, ou que subtrai de uma norma parte da sua matéria para submetê-la a uma regulamentação diferente (contrária ou contraditória).

Veja-se que ainda pode se dar uma antinomia entre duas normas contemporâneas, do mesmo nível e ambas gerais, oportunidade em que, neste caso, os três critérios não ajudam mais, devendo-se utilizar um critério retirado da própria forma da norma.

Segundo a forma, para Bobbio, as normas podem ser 'imperativas', "proibitivas" ou "permissivas". O critério com respeito à forma consistiria em estabelecer uma graduação de prevalência entre as três formas da norma jurídica, deste modo: se de duas normas incompatíveis uma é imperativa ou proibitiva, e a outra é permissiva, prevalece a permissiva. Esse critério parece razoável e correspondente a um dos cânones inter-relativos mais constantemente seguidos pelos juristas, que é o de dar preponderância, em caso de ambiguidade ou de incerteza na interpretação de um texto, à interpretação favorabilis sobre a odiosa. Em linhas gerais, caso se entenda por lex favorabilis aquela que concede uma liberdade (ou faculdade, ou direito subjetivo), e por lex odiosa aquela que impõe obrigação (seguida por sanção), ou proíbe/ restringe interesse, não há dúvida de que a lex permissiva é favorabilis e que a lex imperativa é odiosa(17).

E por que isto é assim nesta perspectiva neopositivista? Porque quando duas normas contraditórias são, ambas, válidas, e pode haver indiferentemente a aplicação de uma ou de outra, conforme o livre-arbítrio daqueles que são chamados a aplicá-las, são violadas duas exigências fundamentais em que se inspiram ou tendem a inspirar-se os ordenamentos jurídicos contemporâneos: a exigência da certeza (que corresponde ao valor da paz ou da ordem), e a exigência da justiça (que corresponde ao valor da igualdade). Em face disto, impõe-se radicalmente a solução da antinomia.

Segundo as regras de direito intertemporal, a lei posterior revoga a anterior quando expressamente o declare, quando seja com ela incompatível, ou quando regule inteiramente a matéria de que tratava a lei anterior ${ }^{(18)}$.

Destaco propositadamente o elemento incompatibilidade enquanto possibilidade de caracterização antinômica de normas porque, a meu sentir, efetivamente é o caso na espécie sub judice, tendo em conta o conjunto harmônico e integral de normas que estão a reger a proteção dos direitos

(17) BOBBIO, Norbeto. op. cit., p. 99.

(18) Lei de Introdução ao Código Civil, art. 2ำ § $1^{\circ}$. 
das pessoas deficientes, tomando-as aqui como que ordenando que se realizem aqueles objetivos e finalidades (diretrizes, princípios etc.) na maior medida possível(19).

Ora, considerando que a disposição inscrita no art. 127, da LC-RS n. 10.098/94, concedeu direito à servidora estadual à obtenção de licença para acompanhar filho excepcional, com consequente redução de carga horária, dispondo de forma diversa daquela prevista no caput, do art. $1^{\circ}$, da Lei-RS n. 7.868/83, uma vez que impõe condicionante não previsto na regra-matriz primeira, afigura-se inarredável que a interpretação do sistema jurídico sob a matéria está a demandar, para otimizar à máxima potência a proteção dos direitos das pessoas deficientes, que se entenda ter ocorrido o que chamo de não recepção superveniente da Lei estadual de 1983 pela Lei estadual de 1994, ao menos no ponto, outorgando a esta interpretação conforme à Constituição e aos Tratados Internacionais firmados pelo Brasil no particular, para o fim de julgar procedente a pretensão deduzida pela servidora.

Não se mostra plausível a aplicação do princípio da especialidade quanto aos referidos dispositivos, visto que ambas as normas disciplinam exatamente a mesma situação; uma, no entanto, reduzindo a possibilidade de exercício do direito conformado pela outra, por razões quantitativas do mesmo vínculo institucional, o que configura violenta desconsideração à proteção de direito fundamental.

Destarte, conclui-se que resta afastada qualquer discussão atinente à jornada semanal mínima indispensável à percepção de redução de carga horária por servidor público que possua filho com necessidades especiais, seja esta física ou mental, considerando-se as disposições constantes da legislação de regência, na forma acima explicitada.

Por fim, considerando que o debate no presente feito cingiu-se ao fato da autora laborar 40 horas para o Estado do Rio Grande do Sul, porém, em dois vínculos de 20 horas semanais cada, entendi que a sentença deveria ser mantida, visto que a legislação de regência não faz qualquer distinção sobre estas particularidades.

\footnotetext{
(19) Tomo por base o argumento alexiano da otimização de direitos fundamentais, conforme ALEXY, Robert. Teoría de los derechos fundamentales. Madrid: Centro de Estudios Constitucionales, 1997. p. 113 e ss. O caráter dos princípios significa que não se tratam simplesmente de normas vagas, mas que com elas se coloca uma tarefa de otimização. Dita tarefa é, no que tange à forma, jurídica; no que tange ao fundo, é sempre moral. Para Alexy, toda a colisão entre princípios pode expressar-se como uma colisão entre valores e vice-e-versa. A única diferença consiste em que a colisão entre princípios trata da questão do que é devido de maneira definitiva, enquanto que a solução do conflito entre valores responde ao que é de maneira definitiva melhor. Princípios e valores são, portanto, a mesma coisa, contemplado em um caso a partir de uma perspectiva deontológica e, em outro caso, a partir de uma perspectiva axiológica. Isto mostra que o problema das relações de prioridade entre princípios corresponde, em verdade, a um problema de hierarquia de valores.
} 


\section{REFERÊNCIAS BIBLIOGRÁFICAS}

ALEXY, Robert. Teoría de los derechos fundamentales. Madrid: Centro de Estudios Constitucionales, 1997.

BOBBIO, Norberto. Teoria dell'ordinamento giuridico. Milano: Giappichelli, 1985.

DILTHEY, Wilhelm. Introduction to the human sciences: an attempt to lay a foundation for the study of society and history. Detroit: Wayne State University Press, 1987.

DWORKIN, Ronald. Freedom's law: the moral reading of the American constitution. Cambridge, Massachusetts: Harvard University Press, 1996.

GADAMER, Hans Georg. Verdade e método. Rio de Janeiro: Vozes, 1997. El giro hermenéutico. Madrid: Catedra, 1997.

HABERMAS, Jürgen. Escritos sobre moralidad y eticidad. México: Paidós, 2002.

IBDD. Disponível em: <http://www.ibdd.org.br/arquivos/leis/Decreto\%203. 298_99.pdf>. Acesso em: 21 jun. 2010.

LAMEGO, José. Hermenêutica e jurisprudência: análise de uma recepção. Lisboa: Fragmentos, 1990.

LEAL, Rogério Gesta. Hermenêutica e direito: considerações sobre a teoria do direito e os operadores jurídicos. Santa Cruz do Sul: Edunisc, 2000.

MEC. Disponível em: <http://portal.mec.gov.br/seesp/arquivos/pdf/ dec_def.pdf>. Acesso em: 20 jun. 2010.

MENGONI, Luigi. Ermeneutica e dogmatica giuridica. Milano: Giuffrè, 1996.

RIU, Antoni Martinez. Diccionario de filosofia. Madrid: Herder, 1997.

STRECK, Lênio Luis. Hermenêutica jurídica em crise. Porto Alegre: Livraria do Advogado, 2003.

WITTGENSTEIN, Ludwig. Investigações filosóficas. São Paulo: Abril Cultural, 1984. 